AperTO - Archivio Istituzionale Open Access dell'Università di Torino

Genetics, prevalence, screening and confirmation of primary aldosteronism: a position statement and consensus of the Working Group on Endocrine Hypertension of The European Society of Hypertension

This is the author's manuscript

Original Citation:

Availability:

This version is available http://hdl.handle.net/2318/1743139

since 2020-07-06T12:49:10Z

Published version:

DOI:10.1097/HJH.0000000000002510

Terms of use:

Open Access

Anyone can freely access the full text of works made available as "Open Access". Works made available under a Creative Commons license can be used according to the terms and conditions of said license. Use of all other works requires consent of the right holder (author or publisher) if not exempted from copyright protection by the applicable law. 


\section{Genetics, prevalence, screening and confirmation of primary aldosteronism: a position statement and consensus of the Working Group on Endocrine Hypertension of the European Society of Hypertension\#.}

Paolo Mulatero ${ }^{\mathrm{a}}$, Silvia Monticone $\mathrm{a}^{\mathrm{a}}$, Jaap Deinum ${ }^{\mathrm{b}, \mathrm{c}^{*}}$, Laurence Amar ${ }^{\mathrm{d} *}$, Aleksander Prejbisz ${ }^{\mathrm{e}^{*}}$, Maria Christina Zennaro ${ }^{\mathrm{f}, \mathrm{g}}$, Felix Beuschlein ${ }^{\mathrm{h}, \mathrm{i}}$, Gian Paolo Rossi ${ }^{\mathrm{l}}$, Tetsuo Nishikawa ${ }^{\mathrm{m}}$, Alberto Morganti $^{\mathrm{n}}$, Teresa Maria Seccia ${ }^{\mathrm{l}}$, Yen-Hung Lin ${ }^{\mathrm{o}}$, Francesco Fallo ${ }^{\mathrm{p}}$, Jiri Widimsky ${ }^{\mathrm{q}}$.

\#this manuscript was prepared with members of the Primary Aldosteronism Task Force for Clinical Practice Guideline of PA by Japan Endocrine Society (T.N.) and of the Taiwan Society of Aldosteronism (Y.-H. L.).

*equal contribution

a Division of Internal Medicine and Hypertension Unit, Department of Medical Sciences, University of Torino, Via Genova 3, 10126, Torino, Italy.

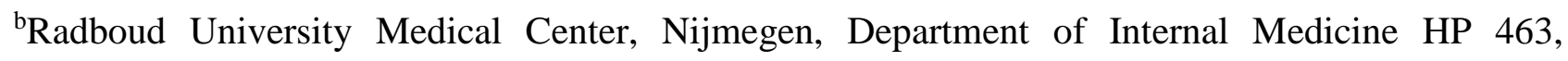
Nijmegen, Netherlands.

'Department of Medicine III, University Hospital Carl Gustav Carus at the TU Dresden, Dresden, Germany.

dHypertension Unit, Assistance Publique-Hôpitaux de Paris, Hôpital européen Georges-Pompidou, Université de Paris, PARCC, Inserm, 75015 Paris,France.

e Department of Hypertension, Institute of Cardiology, Warsaw, Poland.

${ }^{\mathrm{f}}$ Université de Paris, PARCC, INSERM, Paris, France.

gAssistance Publique-Hôpitaux de Paris, Hôpital Européen Georges Pompidou, Service de Génétique, Paris, France. 
hKlinik für Endokrinologie, Diabetologie und Klinische Ernährung, Universitätsspital Zürich, Zürich, Switzerland.

'Medizinische Klinik und Poliklinik IV, Klinikum der Universität München, Munich, Germany.

${ }^{\text {l} H y p e r t e n s i o n ~ U n i t ~ a n d ~ S p e c i a l i z e d ~ C e n t e r ~ f o r ~ B l o o d ~ P r e s s u r e ~ D i s o r d e r s ~-~ D e p a r t m e n t ~ o f ~ M e d i c i n e-~}$ DIMED, University of Padova, Padova, Italy

mEndocrinology and Diabetes Center, Yokohama Rosai Hospital, Yokohama 222-0036, Japan.

${ }^{\text {n}}$ Centro Fisiologia Clinica e Ipertensione, Ospedale Policlinico, Università di Milano, Milan, Italy.

'Division of cardiology, Department of Internal Medicine, National Taiwan University Hospital and National Taiwan University College of Medicine, Taipei, Taiwan.

${ }^{\mathrm{P}}$ Department of Medicine-DIMED, University of Padova, Padova, Italy.

93rd Department of Medicine, Center for Hypertension, General University Hospital and First Faculty of Medicine, Charles University, Prague, Czech Republic.

\section{Corresponding author:}

Paolo Mulatero, MD, Division of Internal Medicine and Hypertension, Department of Medical Sciences, University of Torino, Via Genova 3, 10126, Torino, Italy. Phone: +390116336997 Fax: $+390116336931$

e-mail: paolo.mulatero@unito.it

Word count: abstract: 126; manuscript: 4431 (excluding title page, references, figure legends and table). Number of tables:1. Number of figures:1. Supplementary file: 1.

Key words: primary aldosteronism, aldosterone, renin, saline loading test

Short title: Genetics, prevalence and diagnosis of primary aldosteronism. 


\section{Abstract}

2 Autonomous aldosterone overproduction represents the underlying condition of 5-10\% of patients with arterial hypertension and carries a significant burden of mortality and morbidity. The diagnostic algorithm for primary aldosteronism (PA) is sequentially based on hormonal tests (screening and

5 confirmation tests), followed by lateralization studies (adrenal CT scanning and adrenal venous

6 sampling) to distinguish between unilateral and bilateral disease. Despite the recommendations of the

7 Endocrine Society guideline, PA is largely underdiagnosed and undertreated with high between8 centre heterogeneity. Experts from the European Society of Hypertension have critically reviewed 9 the available literature and prepared a consensus document comprising two articles to summarize 10 current knowledge on the epidemiology, diagnosis, treatment and complications of PA. This position 11 paper also discusses the next challenges and future directions of research in this field.

\section{Condensed abstract}

Primary aldosteronism is the most frequent form of endocrine hypertension and carries an important burden of mortality and morbidity. Despite the availability of the Endocrine Society guideline, PA is largely underdiagnosed and undertreated with high between-centre heterogeneity. This consensus document by the working group on Endocrine Hypertension of the European Society of Hypertension, aims to address the current state-of-the-art in epidemiology, genetics, diagnostic procedures, complications and treatment options for primary aldosteronism. 


\section{INTRODUCTION}

Arterial hypertension represents the leading modifiable risk factor for cardiovascular disease, accounting for 10.4 million deaths globally and 218 million attributable disability-adjusted life-years in 2017 [1]. Over half a century, randomized controlled trials have illustrated the efficacy of blood pressure lowering in reducing the risk of major cardiovascular events, including coronary artery disease, stroke and heart failure [2,3]. Despite a substantial improvement in hypertension awareness, treatment and control since the 1980s, less than half of patients on medication have blood pressure values within the normal range [3,4]. The Lancet Commission on Hypertension recently highlighted that one of the major causes of poor blood pressure control is due to an absent or delayed diagnosis of secondary forms of hypertension [3].

Primary aldosteronism (PA) is widely recognized as the most common form of secondary hypertension [5,6]. Despite this, it remains underdiagnosed and undertreated [7] with an important burden of mortality and morbidity [8,9]. Beyond its classical actions in the epithelium of the distal nephron, colon and salivary glands, where it regulates fluid and electrolyte homeostasis, in the presence of excessive salt intake, aldosterone excess exerts deleterious effects in the vascular system and the kidney, promoting oxidative stress, inflammation and fibrosis, resulting in renal and cardiovascular injury [10].

The Endocrine Society clinical practice guideline for case detection, diagnosis and treatment of patients with PA [11] provides clinicians with the best available research evidence in the field and significantly contributes to improve the quality of care. Since the last update in 2016, clinical management of patients affected by PA has evolved further and important advances have been made in understanding the genetic determinants of PA.

However, the guideline is poorly applied, resulting in a low detection rate of the disease and there is a lack of standardisation of the diagnostic flow-chart. These shortfalls prevent patients from being diagnosed and successfully cured. 
0

The working group on Endocrine Hypertension of the European Society of Hypertension prepared this consensus document to review the available knowledge on genetics, diagnosis, treatment and outcomes of PA and focuses on how to confront unresolved issues in the field.

Part I of the consensus focuses on genetics of sporadic and familial PA, on its relatively high prevalence in patients with hypertension and synthesises the current knowledge on the optimal approaches to diagnose PA, including screening and confirmation testing.

Part II of the consensus presents the most appropriate strategies for subtype differentiation, current treatment approaches, the most common associated cardiovascular and metabolic complications and the established method for evaluation of medical and post-surgical outcomes. We will also give a prospective look on the next challenges and future directions of research in this filed.

At the end of each section a statement summarizes the most important messages. An asterisk indicates the statements that require special attention from non-specialists (such as general practitioners).

\section{WHAT IS PRIMARY ALDOSTERONISM}

PA, also known as Conn syndrome, is a group of pathological conditions associated with an aldosterone secretion inappropriate for sodium intake, that is relatively autonomous from reninangiotensin system activity and potassium levels. Aldosterone production is therefore relatively insensitive to manoeuvres, such as sodium loading, that should suppress its secretion. The high aldosterone production for sodium status is often associated with hypertension, cardiovascular and renal damage, and hypokalaemia. The most common subtypes comprise unilateral aldosteroneproducing adenomas and bilateral hyperaldosteronism; however, a continuum may exist between clearly asymmetrical and bilateral aldosterone excess. Rare subtypes are familial forms and aldosterone-producing carcinoma.

\section{GENETICS}


The approach to human genetics has changed substantially in the past 15 years: the introduction of next-generation sequencing technologies created an unprecedented opportunity to discover germline and somatic disease-causing mutations. The application of next-generation sequencing to the field of PA has given new insight into the molecular mechanisms underlying both sporadic and familial forms.

An extensive description of the genetics of PA, including the role of somatic mutations in the pathogenesis of sporadic PA is available in the supplemental file.

\section{Germline mutations in familial primary aldosteronism.}

While the majority of PA cases are sporadic, up to $5 \%$ of patients may have a familial form of the disease [12]. Four forms of familial hyperaldosteronism (FH), with autosomal dominant transmission and with a known genetic alteration, have been reported so far.

Familial hyperaldosteronism type I (FH-I or glucocorticoid remediable aldosteronism, GRA) is the most common form of monogenic hypertension [13-15]. The diagnosis is based on the amplification of the chimeric CYP11B1/CYP11B2 gene by long-range polymerase chain reaction. Therapeutically, low dose of dexamethasone (such as $0.125-0.25 \mathrm{mg}$ ) to suppress ACTH - alone or in the combination with mineralocorticoid receptor antagonists - is the mainstay of treatment [11]. Patients with PA should be tested for FH-I when there is a family history of PA and/or early onset ( $<20$ years) of the disease or in case of stroke at a young age [11].

Familial hyperaldosteronism type II (FH-II) is an early onset form of PA due to germline mutations in the CLCN2 gene, showing incomplete penetrance $[16,17]$. The diagnosis is made through sequencing of the CLCN2 gene.

Familial hyperaldosteronism type III (FH-III) is a rare form of familial PA, due to germline mutations in the KCNJ5 gene $[14,18,19]$. FH-III should be ruled out in all patients with very early onset PA [11]. Genetic testing is performed by direct KCNJ5 sequencing. 
Familial hyperaldosteronism type IV (FH-IV) is a rare disorder, caused by germline mutations in the CACNA1H gene [20-22]. The diagnosis is made by targeted sequencing of the gene.

A further genetic but not familial form of PA has been described, named PASNA (primary aldosteronism with seizures and neurologic abnormalities) syndrome. It is a very rare condition, characterized by PA and severe neurological impairment [23], reported so far in two paediatric patients. The genetic cause is a de novo gain of function mutation in the CACNA1D gene.

Despite major technological advances facilitating the discovery of disease-causing mutations, the underlying genetic alterations in most families with two or more members affected by PA remain unidentified. This observation raises the possibility that, given the high prevalence of sporadic PA in the general population with hypertension [5], some cases of apparently familial PA may represent coincidental sporadic forms within the same family.

Statement. Considering the relatively low cost and non-invasive nature of genetic testing and the unequivocal benefits of an early diagnosis of a familial disorder, we suggest that genetic testing should be performed in all patients with early onset PA (i.e. $<20$ years of age), irrespective of the severity of the clinical phenotype, and in patients with a family history of PA. The genetic testing of the index patient should be followed by genetic counselling and careful evaluation of first-degree relatives with hypertension to diagnose or exclude PA. Despite the possibility of coincidental occurrence of several sporadic cases in families with two or more affected subjects, genetic testing should be offered.

\section{PREVALENCE OF PRIMARY ALDOSTERONISM}

An expanded prevalence section is available in the supplemental file.

Primary aldosteronism has long been considered a rare condition [24] however, compelling evidence indicates that PA is the most frequent form of secondary hypertension. Unilateral forms of PA (aldosterone-producing adenoma, APA, and unilateral hyperplasia) are effectively treated by 
adrenalectomy, bilateral disease is treated by medical therapy based on mineralocorticoid receptor antagonists (MRAs) [11].

Currently, PA is most often diagnosed by following an algorithm advised by the Endocrine Society guideline task force, [11] based on selecting patients with a higher probability of PA, a screening test (aldosterone-to-renin ratio) and a confirmation test. However, it should be acknowledged that there is a continuum between low-renin primary (essential) hypertension and PA [25, 26] and proof of PA diagnosis is only obtained in patients who fulfill the criteria for biochemical cure after adrenalectomy for unilateral aldosterone overproduction [27]. Out of necessity we therefore depend on confirmatory test results for diagnosis. This group of tests, however, has drawbacks because the predictive properties depend on varying cut-off levels and, when results are indeterminate, are prone to subjective interpretation [11]. In addition to the bias introduced by the absence of well-established reference tests, prevalence studies also suffer from other sources of bias [28, 29].

Moreover, as for any disease condition, the prevalence depends on the population being examined, i.e. unselected hypertensive patients seen in general practice prevalence differ from those in referred patients with hypertension, with stage III and/or drug-resistant hypertension. These factors explain the high heterogeneity of prevalence estimates in different studies [28, 29] and why a recent systematic review, reported figures ranging from 3.2 to $12.7 \%$ in primary practice and from 1 to $30 \%$ in referral centers [28]. PA is an evolving condition starting with a normotensive phase [25] characterized by low renin and minimally elevated aldosterone levels progressing to arterial hypertension with a clear biochemical phenotype. The actual number of patients diagnosed with PA worldwide is likely nowhere near the expected number if all cases are diagnosed, indicating a huge and regrettable under diagnosis of a serious condition $[7,30]$. This raises the question if a systematic screening strategy for PA should be implemented.

\section{Screening for PA in subgroups of hypertensive patients}

The Endocrine Society guideline experts recommended selection of patients with hypertension with a higher probability of PA based on their clinical or biochemical features (Table 1). The subgroups 
of patients with hypertension that may represent increased proportions of patients with PA are discussed further below (Figure 1).

\section{Therapy-resistant hypertension and severe hypertension}

There is little doubt that full-blown PA usually leads to severe hypertension in many cases, which is mostly characterized by either therapy resistance (blood pressure> 140/90 mmHg when on three antihypertensive drugs in adequate dosages, including a diuretic) or blood pressure $>150 / 100 \mathrm{mmHg}$. It is well known that the prevalence of PA increases with the severity of hypertension [5,6,31] and can be as high as $20 \%$ in patients with resistant hypertension [32]. However, in patients with less severe hypertension [5] (or even normotension) [40] PA can also be present and when adopting the approach of subgroup screening these patients may be missed. Whether this leads to worse outcome for these patients is unknown. There are data indicating that the development of PA is gradual [25] and it might well be that patients with a mild phenotype may qualify for screening later in the course of the disease because their hypertension needs increased medication or hypokalemia sets in. This causes a delay and whether this delay leads to a worse cardiovascular prognosis is unknown.

\section{Hypertension at younger age}

Secondary hypertension is relatively more common in children and adolescents than in adults, but endocrine hypertension is thought to be an infrequent cause [41]. Although the idea that younger patients might derive more cardiovascular benefit from treatment for PA and therefore from diagnosis, the median age of patients with PA at the time of diagnosis is close to 50 years [5, 42]. The problem then is, where the cut-off level for age should be for screening? Young patients, for instance $<40$ years, with mild hypertension may have an early stage of PA and may not qualify for screening for other features. The benefit in terms of increased quality of life [43] can be considered at least as relevant to these patients as a better cardiovascular prognosis. There are no data to judge the tradeoff between benefit of early diagnosis and the number of missed diagnoses but younger patients with severe PA will be identified by severity of their hypertension or hypokalemia anyway.

\section{Hypokalemia}


Current recommendations define the normal lower potassium limit from 3.5 to $3.8 \mathrm{mmol} / \mathrm{L}$ [44], with

$<3.5 \mathrm{mmol} / \mathrm{L}$ being the most widely adopted cut-off. However, an increased prevalence of PA was observed in patients affected by arterial hypertension and serum $\mathrm{K}^{+}$comprised between 3.5 and 3.7 mmol/L [35].

While a large number of studies investigated the prevalence of hypokalemia in patients with PA, surprisingly, the prevalence of PA in patients with hypertension and hypokalemia is unknown. Since increased aldosterone leads to potassium loss in the collecting ducts of the kidney, hypokalemia has long been considered an essential feature of PA [24]. However, hypokalemia develops only in a proportion of patients [5,6]. Nonetheless, if present and not explained by other causes, it mandates screening for PA. This applies to diuretic-induced hypokalemia as well, but debate exists whether the cut-off value for screening should be lower than for spontaneous hypokalemia (for instance, $<3$ $\mathrm{mmol} / \mathrm{L}$ instead of $<3.5 \mathrm{mmol} / \mathrm{L}$ ). Although supportive data are lacking, many centers screen for PA in all patients with hypertension who develop potassium levels below the reference range, regardless of diuretic use. In light of recent advances on subclinical PA, future studies should evaluate the efficacy and cost-effectiveness of screening for PA in all patients with spontaneous hypokalemia, regardless of blood pressure values [45].

\section{Adrenal incidentaloma}

The prevalence of PA in patients with an adrenal incidentaloma (defined as adrenal mass detected on imaging performed for other reasons than suspected adrenal disease) is 1.6\%-4.33\% in two studies carried out in Italy and China, respectively [36, 37]. It must be acknowledged that the studies included both patients affected by arterial hypertension and normotensive subjects and the prevalence of PA is expected to significantly increase if considering only patients with $\mathrm{BP} \geq 140 / 90 \mathrm{mmHg}[11,46]$.

\section{Family history of PA or early stroke}

Although monogenic forms of PA are very rare it could be worthwhile to screen for these, especially for glucocorticoid-remediable aldosteronism that is associated with hemorrhagic stroke at a young age [47]. It is likely however that this is warranted for PA at a young age and for first-degree family 
members only. Since PA is so frequent, familial co-occurrence at an older age could also be a coincidence.

\section{Obstructive sleep apnea, metabolic syndrome and diabetes mellitus}

PA is associated with conditions where obesity is a common risk factor such as obstructive sleep apnea (OSA), metabolic syndrome and diabetes mellitus [48]. Several studies reported a higher prevalence of metabolic syndrome and insulin resistance/type 2 diabetes mellitus in patients with PA, and various mechanisms involving the relevance of aldosterone excess in these conditions have been proposed [49, 50]. However, it is still to be confirmed whether higher rates of cardiovascular events reported in PA compared with essential hypertension, may be due to the increased prevalence of these metabolic alterations. With respect to OSA, conclusive evidence for a causative relation is lacking. It has also not been established if this subgroup is more likely to harbor an aldosterone-producing adenoma. According to a single study conducted on 53 patients with OSA the prevalence of PA was 34\%, however the small sample size and some potential selection bias may have affected the results [51]. Despite limited available evidence, the 2016 Endocrine Society guideline recommends screening for PA in all patients with hypertension and OSA (regardless of hypertension grade) [11]. In the recent cross-sectional multi-ethnic HYPNOS study, including 203 patients with OSA, the prevalence of PA was found to be $8.9 \%$ [38], a figure not significantly different either from the prevalence reported in the general population with hypertension [5] or in tertiary referral centres [6]. Notably, when considering only patients without other indications for PA screening (SBP above 150 mmHg, DBP above $100 \mathrm{mmHg}$ or hypokalemia) the prevalence dropped to $1.5 \%$, challenging the current recommendation of the Endocrine Society guideline [38].

\section{Atrial fibrillation}

It is now well established that atrial fibrillation is a complication of PA with an unusually high incidence [9]. It is therefore conceivable that in cohorts with lone atrial fibrillation and hypertension, where atrial fibrillation is ascribed to hypertension and hypokalemia attributed to diuretic use, the prevalence of PA can be particularly high [39]. This leads to the consideration of screening for PA in 
patients with hypertension and atrial fibrillation unexplained by structural heart defects and/or other conditions known to cause the arrhythmia. This contention is also supported by the observation that identification of unilateral PA followed by surgery decreased incident atrial fibrillation during longterm follow-up [52].

Statement*. Available evidence indicates that PA is far more common than generally considered, and even if the real prevalence is not easily assessed, there is clearly a large gap between the number of patients diagnosed and the actual number of patients with PA. Screening categories of patients with hypertension advocated by the Endocrine Society guideline, with the exception of those with obstructive sleep apnea, and extending screening to patients with unexplained atrial fibrillation may help bridge this gap.

\section{DIAGNOSIS OF PRIMARY ALDOSTERONISM}

According to the Endocrine Society guideline, the diagnosis of PA should follow a three-step approach in the vast majority of cases (Figure 1), comprising I) screening II) confirmation/exclusion testing and III) subtype diagnosis to distinguish unilateral from bilateral disease [11]

\section{Screening test}

The most reliable screening test for PA, which should be theoretically highly sensitive, is the calculation of the plasma aldosterone-to-renin ratio (ARR). However, many conditions influence the ARR thereby limiting its accuracy for the diagnosis of PA.

\section{Plasma renin and aldosterone measurements}

More detailed information on hormonal assays is provided in the supplemental file.

The most widely used method for measuring plasma renin is the direct renin concentration (DRC), even though the plasma renin activity (PRA) assay is still used in many centers. 
248 For both DRC and PRA, careful precautions for collecting and processing blood samples at room 249 temperature are essential to prevent inadvertent cryoactivation of plasma prorenin (inactive 250 circulating renin) from a closed to an open conformation. This is particularly relevant in patients with 251 low active renin values such as those with PA [53] in whom levels of inactive renin are particularly 252 high.

253 Plasma aldosterone concentration (PAC) can be measured by radioimmunoassay, immunometric 254 techniques or more recently by ultra-high performance liquid chromatography and tandem mass spectrometry (LC-MS/MS) [54, 55].

\section{Plasma aldosterone to renin ratio (ARR)}

Hiramatsu et al. were the first to report the advantage of using the ARR for the diagnosis of PA in 1981 [56]. ARR has a better sensitivity than the measurement of plasma aldosterone, renin, and potassium concentrations alone [11]. However, several methodological factors might affect the ARR and undermine its diagnostic accuracy. First, due to the lack of accuracy of DRC measurements at low concentrations, some authors recommend setting a minimum value for renin used to calculate the ARR. Some studies have set this value for DRC at $5 \mathrm{mUI} / \mathrm{L}[54,57]$. Second, different cut-offs have been proposed using different units of measurement for both renin and aldosterone concentrations. Third, the method used to measure PAC may also have an impact on the ARR threshold. Indeed, the aldosterone range using LC-MS/MS is usually 30\% lower that measured with radioimmunoassay [54, 55] and adjustment of the current cut-offs for PA diagnostic testing is deemed necessary if PAC is cut-offs to define a positive ARR is 30, when aldosterone is measured in ng/dL and PRA in ng/mL/h, which should correspond to 3.7 if DRC is measured in mUI/L and a conversion factor of 8.2 is used, measured by LC-MS/MS.

Given the heterogeneity of assay methods for measuring both PRA or DRC and aldosterone, various thresholds for ARR are used in different centers. As reported in Table 2, the most widely adopted as suggested by the Endocrine Society guideline [11]. 
However, in light of recent studies comparing the performances of PRA and DRC, we suggest that a lower cut-off (between 1.12 and 2.7) [58-60] should be adopted with chemiluminescent methods.

275 Given the low correlation between PRA and DRC for PRA values $<1 \mathrm{ng} / \mathrm{mL} / \mathrm{h}$ we discourage using a direct conversion between DRC and PRA values. The most recent studies using LC-MS/MS as a reference standard for aldosterone measurements, propose thresholds of $45 \mathrm{pmol} / \mathrm{mU}$ (aldosterone in $\mathrm{pmol} / \mathrm{L}$ and $\mathrm{DRC}$ in $\mathrm{mUI} / \mathrm{L}$, with a minimum set at $5 \mathrm{mUI} / \mathrm{L}$; the threshold is 1.6 if aldosterone is measured in ng/dL) [54] or a threshold of $55 \mathrm{pmol} / \mathrm{mUI}$ without a minimum for DRC [55]. low plasma aldosterone levels, and thus it is important to include a minimum PAC for screening criteria. Some authors suggest $15 \mathrm{ng} / \mathrm{dL}[61,62]$, while others suggest that the PAC at the screening test should not be lower that the cut-off used to define aldosterone suppression at the confirmatory test [63]. Ideally, in the view of the very large variability of the different thresholds, each laboratory should determine its own cut-off using the best available methods to measure renin and aldosterone and avoid interfering drugs at the time of blood sampling collection (see below).

\section{Drug interference}

Medications used to treat patients with arterial hypertension usually interfere with the regulation of the renin-angiotensin system (RAS) and can therefore modify plasma concentrations of both renin and aldosterone and hence the ARR [64].

An extended analysis of the effects of anti-hypertensive drugs on the ARR is available in the supplemental file and supplemental table S1.

293 The interference of multiple drugs given in combination on the ARR is highly variable depending on 294 the classes and doses of the drug combination [65]. In particular, MR antagonists and $\beta$-blockers might be associated with false negative and false positive results, making the ARR difficult to interpret. Ideally, it would be preferable to stop interfering drugs before measuring the ARR. 
298 known effects of antihypertensive medications, even under ACE-inhibitors, angiotensin II receptor 299 blockers and low-doses diuretics except MRAs [11, 62] (supplemental table S1).

300 The delay for withdrawal of the drugs is also heterogeneous ranging from 2 to 4 weeks for beta 301 blockers, ACE inhibitors, ARB, dihydropyridines and diuretics and from 4 to 6 weeks for 302 spironolactone or eplerenone $[11,66]$. When the complete cessation of all antihypertensive 303 medication is not feasible, the patient should be treated with medications that have only a minimal 304 impact on ARR (non-DHP CCBs, hydralazine, $\alpha_{1}$-antagonists and moxonidine) [11,67]. The 305 replacement of interfering drugs by non-interfering ones according to a standardized protocol or even 306 drug discontinuation did not confer any increased risk of acute cardiovascular events when performed 307 in well-controlled settings in specialized hospitals and using home-BP monitoring [68]. However, 308 precautions are mandatory in high risk patients [69]. Other drugs known to interfere with the RAS 309 are listed in supplemental table S1.

\section{Other conditions influencing renin and aldosterone determinations}

311 It is well known that, under physiological conditions and "normal” RAAS regulation, a high sodium 312 diet lowers renin more than aldosterone, potentially leading to false positive results. On the contrary, 313 low sodium diet increases plasma renin and, to a lesser extent, aldosterone levels, leading to false 314 negative ARR results and according to a recent study, increases the risk of misinterpreting milder 315 cases of primary aldosteronism [70]. It is usually recommended to measure plasma renin and 316 aldosterone on a free dietary salt intake [11] and verification of $\mathrm{Na}^{+}$intake at the time of ARR testing 317 is worth consideration [70].

318 A diffuse evaluation of other factor acting on renin and aldosterone measurements, including timing 319 of the blood withdrawal, posture and food intake, the influence of gender, race and ethnicity is 320 available in the supplemental file. 
Despite identical time of blood sampling during the day, posture and medication intake, there is a day-to-day variability in the ARR. Rossi and coworkers report a good within-patient reproducibility of ARR in PA [71]. However, other studies have found that up to a $1 / 3$ of patients with PA had an ARR in the normal range at some timepoint during their diagnostic workup [72]. It is thus recommended that ARR is assessed at least twice in patients with a low renin profile $[66,73,74]$ but this is not mandatory for patients with elevated renin levels.

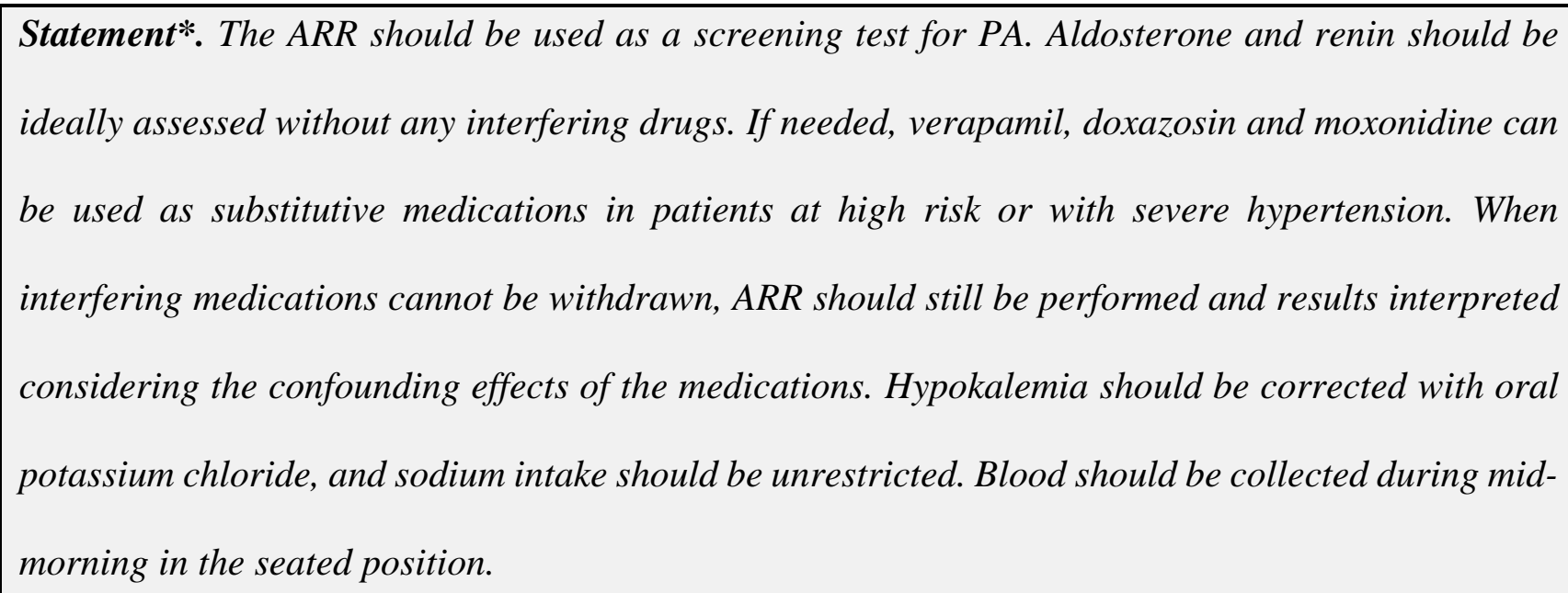
ideally assessed without any interfering drugs. If needed, verapamil, doxazosin and moxonidine can be used as substitutive medications in patients at high risk or with severe hypertension. When interfering medications cannot be withdrawn, ARR should still be performed and results interpreted considering the confounding effects of the medications. Hypokalemia should be corrected with oral potassium chloride, and sodium intake should be unrestricted. Blood should be collected during midmorning in the seated position.

\section{Confirmatory/Exclusion tests}

Given the low specificity of the ARR for PA diagnosis, one or more confirmatory tests should be performed to definitively demonstrate the non-suppressibility of aldosterone production and to avoid an expensive, time-consuming and invasive work-up (Figure 1) [11,75]. It has been shown that the specificity of the ARR for PA diagnosis increases, and conversely the false positive rate decreases, with rising ARR values [57], and under predefined circumstances, i.e. spontaneous hypokalemia together with PAC > $20 \mathrm{ng} / \mathrm{dL}$ and PRA (or DRC) below assay detection limits, patients may proceed directly to PA subtyping [11].

Four testing procedures are currently recommended by the Endocrine Society guideline: fludrocortisone suppression test (FST), oral sodium loading test (SLT), saline infusion test (SIT) and captopril challenge test (CCT) [11]. To date, according to available literature, there is not enough 
evidence to recommend one test over the others; protocol, interpretation, advantages and drawbacks of each test are detailed in supplemental table S2. As for screening, confirmatory testing requires standardized conditions: potassium levels should be checked and hypokalemia corrected and interfering antihypertensive drugs must be considered to avoid false positive or false negative results. Over the last 20 years several studies attempted to compare the performances of two or more confirmatory testing in the diagnosis of PA, however they suffer from several limitations, including the retrospective nature, the different cut-offs adopted and, most importantly, the fact that often one test was arbitrarily chosen as a reference standard over the others $[11,76]$ with the exception of the AQUARR Study [57]. A recent prospective study compared, with a robust methodology, the performances of SIT and CCT, using the FST as reference [77]. A total of 236 patients (129 with an ARR $>3.7 \mathrm{ng}^{*} \mathrm{dL}^{-1} / \mathrm{mIU}^{*} \mathrm{~L}^{-1}$ and 107 with an ARR $\left.<3.7\right)$ completed all three confirmatory test procedures. Using post-test PAC to establish PA diagnosis, both SIT and CCT resulted as valid alternatives to the cumbersome FST, while the areas under the receiver-operator characteristics curves of the CCT fell significantly when considering the percentage of PAC reduction [77]. Similar results were obtained by Meng et al in the Chinese population [78].

Stowasser et al. showed higher sensitivity of seated SIT (post-SIT plasma aldosterone concentration cut-off $5.84 \mathrm{ng} / \mathrm{dL}$ ) compared with recumbent SIT (post-SIT plasma aldosterone concentration, cutpoint: 3.82 ng/dl; 87\% vs. 38\%), and similar specificity (94\% vs 94\%) [79]. Of note, PAC after seated SIT outperforms PAC post-CCT in predicting clinical outcomes after adrenalectomy in PA patients [80].

Overall, seated SIT appears reliable and less complicated than FST and SLT. CCT may be a good alternative in patients at risk of potential fluid overload, eg. patients with renal insufficiency or heart failure [77, 79].

However, there is wide variability in both the choice of confirmatory test and in cut-off values between referral centers, because of differences in patient characteristics and technical facilities. For 
example, the cut point of post seated SIT plasma aldosterone concentration ranges from $5 \mathrm{ng} / \mathrm{dL}$ [5] 375 to $16 \mathrm{ng} / \mathrm{dl}[81,82]$.

Statement*. Positive ARR screening for PA must be confirmed by one of four confirmatory tests. However, in patients with 1) spontaneous hypokalemia 2) PAC >20 ng/dL (550 pmol/L) and 3) PRA (or DRC) below assay detection limits, the diagnosis of PA can be made on increased ARR alone. Seated saline infusion confirmatory testing may have the best trade-off between performance and limitations. In patients at risk of potential fluid overload, the captopril challenge test may be preferred. When captopril challenge testing is performed, the evaluation of absolute aldosterone levels is recommended over percent reductions. 


\section{References}

1. GBD 2017 Risk Factor Collaborators. Global, regional, and national comparative risk assessment of 84 behavioural, environmental and occupational, and metabolic risks or clusters of risks for 195 countries and territories, 1990-2017: a systematic analysis for the Global Burden of Disease Study 2017. Lancet 2018; 392:1923-1994

2. Ettehad D, Emdin CA, Kiran A, Anderson SG, Callender T, Emberson J et al. Blood pressure lowering for prevention of cardiovascular disease and death: a systematic review and metaanalysis. Lancet 2016; 387:957-967

3. Olsen MH, Angell SY, Asma S, Boutouyrie P, Burger D, Chirinos JA et al. A call to action and a lifecourse strategy to address the global burden of raised blood pressure on current and future generations: the Lancet Commission on hypertension. Lancet 2016; 388:2665-2712

4. Chow CK, Teo KK, Rangarajan S, Islam S, Gupta R, Avezum A et al. Prevalence, awareness, treatment, and control of hypertension in rural and urban communities in high-, middle-, and lowincome countries. JAMA 2013; 310:959-968

5. Monticone S, Burrello J, Tizzani D, Bertello C, Viola A, Buffolo F et al. Prevalence and clinical manifestations of primary aldosteronism encountered in primary care practice. J Am Coll Cardiol 2017; 69:1811-1820

6. Rossi GP, Bernini G, Caliumi C, Desideri G, Fabris B, Ferri C et al. A prospective study of the prevalence of primary aldosteronism in 1,125 hypertensive patients. J Am Coll Cardiol 2006; 48:2293-2300

7. Mulatero P, Monticone S, Burrello J, Veglio F, Williams TA, Funder J. Guidelines for primary aldosteronism: uptake by primary care physicians in Europe. J Hypertens 2016; 34:2253-2257 
8. Reincke M, Fischer E, Gerum S, Merkle K, Schulz S, Pallauf A et al. Observational study mortality in treated primary aldosteronism: the German Conn's registry. Hypertension 2012; 60:618-624

9. Monticone S, D'Ascenzo F, Moretti C, Williams TA, Veglio F, Gaita et al. Cardiovascular events and target organ damage in primary aldosteronism compared with essential hypertension: a systematic review and meta-analysis. Lancet Diabetes Endocrinol 2018; 6:41-50

10. Briet M and Schiffrin E. Aldosterone: effects on the kidney and cardiovascular system. Nat Rev Nephrol 2010; 6:261-273

11. Funder JW, Carey RM, Mantero F, Murad MH, Reincke M, Shibata H et al. The Management of Primary Aldosteronism: Case Detection, Diagnosis, and Treatment: An Endocrine Society Clinical Practice Guideline. J Clin Endocrinol Metab 2016; 101:1889-1916

12. Mulatero P, Tizzani D, Viola A, Bertello C, Monticone S, Mengozzi G et al. Prevalence and characteristics of familial hyperaldosteronism: the PATOGEN study (Primary Aldosteronism in TOrino-GENetic forms). Hypertension 2011; 58:797-803

13. Monticone S, Buffolo F, Tetti M, Veglio F, Pasini B, Mulatero P. GENETICS IN ENDOCRINOLOGY: The expanding genetic horizon of primary aldosteronism. Eur J Endocrinol 2018; 178:R101-R111

14. Prada ETA, Burrello J, Reincke M, Williams TA. Old and New Concepts in the Molecular Pathogenesis of Primary Aldosteronism. Hypertension 2017; 70:875-881

15. Lifton RP, Dluhy RG, Powers M, Rich GM, Cook S, Ulick S et al. A chimaeric 11 betahydroxylase/aldosterone synthase gene causes glucocorticoid-remediable aldosteronism and human hypertension. Nature 1992; 355:262-5 
16. Scholl UI, Stölting G, Schewe J, Thiel A, Tan H, Nelson-Williams C et al. CLCN2 chloride channel mutations in familial hyperaldosteronism type II. Nat Genet 2018; 50:349-354

17. Fernandes-Rosa FL, Daniil G, Orozco IJ, Göppner C, El Zein R, Jain V et al. A gain-offunction mutation in the CLCN2 chloride channel gene causes primary aldosteronism. Nat Genet 2018; 50:355-361

18. Choi M, Scholl UI, Yue P, Björklund P, Zhao B, Nelson-Williams C. et al. K+ channel mutations in adrenal aldosterone-producing adenomas and hereditary hypertension. Science 2011; 331:768-772

19. Monticone S, Tetti M, Burrello J, Buffolo F, De Giovanni R, Veglio F et al. Familial hyperaldosteronism type III. J Hum Hypertens 2017; 31:776-781

20. Scholl UI, Stölting G, Nelson-Williams C, Vichot AA, Choi M, Loring E et al. Recurrent gain of function mutation in calcium channel CACNA1H causes early-onset hypertension with primary aldosteronism. Elife 2015; 4:e06315

21. Reimer EN, Walenda G, Seidel E, Scholl UI. CACNA1H(M1549V) mutant calcium channel causes autonomous aldosterone production in HAC15 cells and is inhibited by mibefradil. Endocrinology 2016; 157:3016-3022

22. Daniil G, Fernandes-Rosa FL, Chemin J, Blesneac I, Beltrand J, Polak M et al. CACNA1H mutations are associated with different forms of primary aldosteronism. EBioMedicine 2016; 13:225-236

23. Scholl UI, Goh G, Stölting G, de Oliveira RC, Choi M, Overton JD et al. Somatic and germline CACNA1D calcium channel mutations in aldosterone-producing adenomas and primary aldosteronism. Nat Genet 2013; 45:1050-1054 
25. Brown JM, Robinson-Cohen C, Luque-Fernandez MA, Allison MA, Baudrand R, Ix JH et al. The spectrum of subclinical primary aldosteronism and incident Hypertension: a cohort study. Ann Intern Med 2017; 167:630-641

26. Monticone S, Losano I, Tetti M, Buffolo F, Veglio F, Mulatero P. Diagnostic approach to low-renin hypertension. Clin Endocrinol (Oxf) 2018; 89:385-396

27. Williams TA, Lenders JWM, Mulatero P, Burrello J, Rottenkolber M, Adolf C et al. Outcomes after adrenalectomy for unilateral primary aldosteronism: an international consensus on outcome measures and analysis of remission rates in an international cohort. Lancet Diabetes Endocrinol 2017; 5:689-699

28. Kayser SC, Dekkers T, Groenewoud HJ, van der Wilt GJ, Carel Bakx J, van der Wel MC et al. Study heterogeneity and estimation of prevalence of primary aldosteronism: a systematic review and meta-regression analysis. J Clin Endocrinol Metab 2016; 101:2826-2835

29. Buffolo F, Monticone S, Burrello J, Tetti M, Veglio F, Williams TA et al. Is Primary Aldosteronism Still Largely Unrecognized? Horm Metab Res 2017; 49:908-914

30. Rossi E, Perazzoli F, Negro A, Magnani A. Diagnostic rate of primary aldosteronism in Emilia-Romagna, Northern Italy, during 16 years (2000-2015). J Hypertens 2017; 35:1691-1697

31. Mosso L, Carvajal C, González A, Barraza A, Avila F, Montero J et al. Primary aldosteronism and hypertensive disease. Hypertension 2003; 42:161-165

32. Calhoun DA, Nishizaka MK, Zaman MA, Thakkar RB, Weissmann P. Hyperaldosteronism among black and white subjects with resistant hypertension. Hypertension 2002; 40:892-896 
33. Ma L, Song Y, Mei M, He W, Hu J, Cheng Q et al. Age-related cutoffs of plasma aldosterone/renin concentration for primary aldosteronism screening. Int J Endocrinol 2018; 8647026

34. Martinez-Aguayo A, Aglony M, Campino C, Garcia H, Bancalari R, Bolte L et al. Aldosterone, plasma Renin activity, and aldosterone/renin ratio in a normotensive healthy pediatric population. Hypertension 2010; 56:391-396

35. Burrello J, Monticone S, Losano I, Cavaglià G, Buffolo F, Tetti M et al. Prevalence of Hypokalemia and Primary Aldosteronism in 5100 Patients Referred to a Tertiary Hypertension Unit. Hypertension 2020; 75:1025-1033

36. Mantero F, Terzolo M, Arnaldi G, Osella G, Masini AM, Ali A et al. A survey on adrenal incidentaloma in Italy. Study group on adrenal tumors of the Italian Society of Endocrinology. J Clin Endocrinol Metab 2000; 85:637-644

37. Li L, Yang G, Zhao L, Dou J, Gu W, Lv Z, Lu J, Mu Y. Baseline Demographic and Clinical Characteristics of Patients with Adrenal Incidentaloma from a Single Center in China: A Survey. Int J Endocrinol 2017; 2017:3093290.

38. Buffolo F, Li Q, Monticone S, Heinrich DA, Mattei A, Pieroni J et al. Primary aldosteronism and obstructive sleep apnea: a cross-sectional multi-ethnnic study. Hypertension 2019; 74:15321540

39. Seccia TM, Letizia C, Muiesan ML, Lerco S, Cesari M, Bisogni V et al. Atrial fibrillation as presenting sign of Primary Aldosteronism: results of the PAPPHY Study. J Hypertens 2020; 38:332-339.

40. Baudrand R, Guarda FJ, Fardella C, Hundemer G, Brown J, Williams G et al. Continuum of renin-independent aldosteronism in normotension. Hypertension 2017; 69:950-956 
41. Flynn JT, Kaelber DC, Baker-Smith CM, Blowey D, Carroll AE, Daniels SR et al. Clinical practice guideline for screening and management of high blood pressure in children and adolescents. Pediatrics 2017; 140 pii: e20171904

42. Dekkers T, Prejbisz A, Kool LJS, Groenewoud H, Velema M, Spiering W et al. Adrenal vein sampling versus CT scan to determine treatment in primary aldosteronism: an outcome-based randomised diagnostic trial. Lancet Diabetes Endocrinol 2016; 4:739-446

43. Velema M, Dekkers T, Hermus A, Timmers H, Lenders J, Groenewoud H et al. Quality of life in primary aldosteronism: a comparative effectiveness study of adrenalectomy and medical treatment. J Clin Endocrinol Metab 2018; 103:16-24

44. Macdonald JE, Struthers AD. What is the optimal serum potassium level in cardiovascular patients? J Am Coll Cardiol 2004; 43:155-161.

45. Vaidya A, Mulatero P, Baudrand R, Adler GK. The expanding spectrum of primary aldosteronism: implications for diagnosis, pathogenesis, and treatment. Endocr Rev 2018; 39:1057-1088

46. Fassnacht M, Arlt W, Bancos I, Dralle H, Newell-Price J, Sahdev A et al. Management of adrenal incidentalomas: European Society of Endocrinology Clinical Practice Guideline in collaboration with the European Network for the Study of Adrenal Tumors. Eur J Endocrinol 2016; 175:G1-G34

47. Litchfield WR, Anderson BF, Weiss RJ, Lifton RP, Dluhy RG. Intracranial aneurysm and hemorrhagic stroke in glucocorticoid-remediable aldosteronism. Hypertension 1998; 31:445-50

48. Dudenbostel T, Calhoun DA. Resistant hypertension, obstructive sleep apnoea and aldosterone. J Hum Hypertens 2012; 26:281-287 
49. Fallo F, Pilon C, Urbanet R. Primary aldosteronism and metabolic syndrome. Horm Metab Res 2012; 44:208-214.

50. Gerards J, Heinrich DA, Adolf C, Meisinger C, Rathmann W, Sturm L et al. Impaired glucose metabolism in primary aldosteronism is associated with cortisol cosecretion. J Clin Endocrinol Metab 2019; 104:3192-3202

51. Di Murro A, Petramala L, Cotesta D, Zinnamosca L, Crescenzi E, Marinelli C et al. Reninangiotensin-aldosterone system in patients with sleep apnoea: prevalence of primary aldosteronism. J Renin Angiotensin Aldosterone Syst 2010; 11:165-172

52. Rossi GP, Maiolino G, Flego A, Belfiore A, Bernini G, Fabris B et al. Adrenalectomy lowers incident atrial fibrillation in primary aldosteronism patients at long term. Hypertension 2018; 71:585-591

53. Campbell DJ, Nussberger J, Stowasser M, Danser AHJ, Morganti A, Frandsen E et al. Activity assays and immunoassays for plasma renin and prorenin: information provided and precautions necessary for accurate measurement. Clinical Chemistry 2009; 55:867-877

54. Baron S, Amar L, Faucon A-L, Blanchard A, Baffalie L, Faucard C et al. Criteria for diagnosing primary aldosteronism on the basis of liquid chromatography-tandem mass spectrometry determinations of plasma aldosterone concentration. J Hypertens 2018; 36: 15921601

55. Guo Z, Poglitsch M, McWhinney BC, Ungerer JPJ, Ahmed AH, Gordon RD et al. Aldosterone LC-MS/MS assay-specific threshold values in screening and confirmatory testing for primary aldosteronism. J Clin Endocrinol Metab 2018; 103: 3965-3973 
56. Hiramatsu K, Yamada T, Yukimura Y, Komiya I, Ichikawa K, Ishihara M et al. A screening test to identify aldosterone-producing adenoma by measuring plasma renin activity. Results in hypertensive patients. Arch Intern Med 1981; 141:1589-1593

57. Maiolino G, Rossitto G, Bisogni V, Cesari M, Seccia TM, Plebani M et al. Quantitative value of aldosterone-renin ratio for detection of aldosterone-producing adenoma: the aldosterone-renin ratio for primary aldosteronism (AQUARR) study. J Am Heart Assoc 2017; 6:pii: e005574

58. Burrello J, Monticone S, Buffolo F, Lucchiari M, Tetti M, Rabbia F et al. Diagnostic accuracy of aldosterone and renin measurement by chemiluminescent immunoassay and radioimmunoassay in primary aldosteronism. J Hypertens 2016; 34:920-927

59. Manolopoulou J, Fischer E, Dietz A, Diederich S, Holmes D, Junnila R et al. Clinical validation for the aldosterone-to-renin ratio and aldosterone suppression testing using simultaneous fully automated chemiluminescence immunoassays. J Hypertens 2015; 33:25002511

60. Rossi GP, Ceolotto G, Rossitto G, Seccia TM, Maiolino G, Berton C et al. Prospective validation of an automated chemiluminescence-based assay of renin and aldosterone for the workup of arterial hypertension. Clin Chem Lab Med 2016; 54:1441-1450

61. Mulatero P, Monticone S, Bertello C, Tizzani D, Iannaccone A, Crudo V et al. Evaluation of primary aldosteronism. Curr Opin Endocrinol Diabetes Obes 2010; 17:188-193

62. Young WF Jr. Diagnosis and treatment of primary aldosteronism: practical clinical perspectives. J Intern Med 2019; 285:126-148

63. Wolley MJ, Stowasser M. New advances in the diagnostic work-up of primary aldosteronism. J Endocr Soc 2017; 1:149-161 

aldosterone/plasma renin activity ratio in primary aldosteronism. Hypertension 2002; 40:897-902 65. Seifarth C, Trenkel S, Schobel H, Hahn EG, Hensen J. Influence of antihypertensive medication on aldosterone and renin concentration in the differential diagnosis of essential hypertension and primary aldosteronism. Clin Endocrinol 2002; 57:457-465

66. Stowasser M, Ahmed AH, Pimenta E, Taylor PJ, Gordon RD. Factors affecting the aldosterone/renin ratio. Horm Metab Res 2012; 44:170-176

67. Ahmed AH, Gordon RD, Ward G, Wolley M, McWhinney BC, Ungerer JP et al. Effect of moxonidine on the aldosterone/renin ratio in healthy male volunteers. J Clin Endocrinol Metab 2017; 102: 2039-2043

68. Beeftink MM, van der Sande NG, Bots ML, Doevendans PA, Blankestijn PJ, Visseren FL et al. Safety of temporary discontinuation of antihypertensive medication in patients with difficultto-control hypertension. Hypertension 2017; 69:927-932

69. Fischer E, Beuschlein F, Bidlingmaier M, Reincke M. Commentary on the endocrine society practice guidelines: consequences of adjustment of antihypertensive medication in screening of primary aldosteronism. Rev Endocr Metab Disord 2011; 12:43-48

70. Baudrand R, Guarda FJ, Torrey J, Williams G, Vaidya A. Dietary Sodium Restriction Increases the Risk of Misinterpreting Mild Cases of Primary Aldosteronism. J Clin Endocrinol Metab 2016; 101:3989-3996

71. Rossi GP, Seccia MT, Palumbo G, Belfiore A, Bernini G, Caridi G et al. Within-patient reproducibility of the aldosterone: renin ratio in primary aldosteronism. Hypertension 2010; 55:83-89 
72. Tanabe A, Naruse M, Takagi S, Tsuchiya K, Imaki T, Takano K. Variability in the renin/aldosterone profile under random and standardized sampling conditions in primary aldosteronism. J Clin Endocrinol Metab 2003; 88:2489-2494

73. Amar L, Baguet JP, Bardet S, Chaffanjon P, Chamontin B, Douillard C et al. SFE/SFHTA/AFCE Primary aldosteronism consensus: introduction and handbook. Ann Endocrinol (Paris) 2016; 77:179-186

74. Gordon RD. The challenge of more robust and reproducible methodology in screening for primary aldosteronism. J Hypertens 2004; 22:251-255

75. Reznik Y, Amar L, Tabarin A. SFE/SFHTA/AFCE consensus on primary aldosteronism, part 3: Confirmatory testing. Annal Endocrinol (Paris) 2016; 77:202-207

76. Morera J, Reznik Y. MANAGEMENT OF ENDOCRINE DISEASE: The role of confirmatory tests in the diagnosis of primary aldosteronism. Eur J Endocrinol 2019; 180:R45R58

77. Song Y, Yang S, He W, Hu J, Cheng Q, Wang Y et al. Confirmatory tests for the diagnosis of primary aldosteronism: a prospective diagnostic accuracy study. Hypertension 2018; 71:118124

78. Meng X, Li Y, Wang X, Li J, Liu Y, Yu Y. Evaluation of the saline infusion test and the captopril challenge test in chinese patients with primary aldosteronism. J Clin Endocrinol Metab 2018; 103:853-860

79. Stowasser M, Ahmed AH, Cowley D, Wolley M, Guo Z, McWhinney BC et al. Comparison of seated with recumbent saline suppression testing for the diagnosis of primary aldosteronism. $\mathrm{J}$ Clin Endocrinol Metab 2018; 103:4113-4124 
80. Wu CH, Wu VC, Yang YW, Lin YH, Yang SY, Lin PC et al. Plasma aldosterone after seated saline infusion test outperforms captopril test at predicting clinical outcomes after adrenalectomy for primary aldosteronism. Am J Hypertens 2019; 16; 32:1066-1074

81. Wu CH, Wu VC, Yang YW, Lin YH, Yang SY, Lin PC et al. Plasma aldosterone after seated saline infusion test outperforms captopril test at predicting clinical outcomes after adrenalectomy for primary aldosteronism. Am J Hypertens 2019; 16; 32:1066-1074

82. Wu VC, Hu YH, Er LK, Yen RF, Chang CH, Chang YL et al. Case detection and diagnosis of primary aldosteronism - The consensus of Taiwan Society of Aldosteronism. J Formos Med Assoc 2017; 116:993-1005

Figure legends

Figure 1.

Proposed diagnostic flow-chart for patients with PA.

*For patients with PA and age $<35$ years + aldosterone $>30 \mathrm{ng} / \mathrm{dL}+$ unilateral adenoma $(>10$ mm) + normal contralateral adrenal at CT scan, adrenalectomy without AVS requirement has been suggested [11], based on 3 studies [50-52]. However, some authors prefer to perform AVS in all

17 patients. 


\begin{tabular}{|c|c|c|}
\hline Subgroup & $\begin{array}{l}\text { Recommendation to } \\
\text { screen for PA }\end{array}$ & Comment \\
\hline $\begin{array}{l}\text { Therapy-resistant } \\
\text { hypertension/grade } 3 \\
\text { hypertension }\end{array}$ & Yes & $\begin{array}{l}\text { Prevalence of PA increases with the } \\
\text { severity of hypertension }[5,6,31,32]\end{array}$ \\
\hline $\begin{array}{l}\text { Hypertension at young age } \\
\text { ( }<40 \text { year old })\end{array}$ & $\begin{array}{l}\text { Probably, may require } \\
\text { lower cut-offs }\end{array}$ & $\begin{array}{l}\text { No data to confirm high } \\
\text { prevalence/benefit in young patients with } \\
\text { hypertension }[33,34]\end{array}$ \\
\hline Hypokalemia & Yes & $\begin{array}{l}\text { PA prevalence in patients affected by } \\
\text { hypertension and serum } \mathrm{K}^{+}<3.7 \mathrm{mmol} / \mathrm{L} \\
\text { is } 28.1 \% \text { and rises up to } 88.5 \% \text { in patients } \\
\text { with spontaneous hypokalemia of }<2.5 \\
\mathrm{mmol} / \mathrm{L} \text { [35] }\end{array}$ \\
\hline Adrenal incidentaloma & Yes & $\begin{array}{l}\text { Prevalence of PA in patients with adrenal } \\
\text { incidentaloma is } 1.6 \%-4.33 \%[36,37]^{*}\end{array}$ \\
\hline $\begin{array}{l}\text { Family history of PA/early } \\
\text { stroke }\end{array}$ & Yes & $\begin{array}{l}\text { Only in young, first-degree relatives with } \\
\text { hypertension }\end{array}$ \\
\hline $\begin{array}{l}\text { Obstructive sleep apnea, } \\
\text { obesity }\end{array}$ & No & $\begin{array}{l}\text { The vast majority of patients with PA are } \\
\text { tested for blood pressure levels grade } \geq 2 \\
\text { or hypokalemia [38] }\end{array}$ \\
\hline Atrial fibrillation & Yes & $\begin{array}{l}\text { If unexplained by structural heart disease } \\
\text { and other conditions like hyperthyroidism } \\
\text { [39] }\end{array}$ \\
\hline Grade 2 hypertension & Yes & $\begin{array}{l}\text { Especially if treatment response is poor; } \\
\text { Prevalence of PA increases with the } \\
\text { severity of hypertension }[5,6,31]\end{array}$ \\
\hline Grade 1 hypertension & Doubtful & $\begin{array}{l}\text { Balance between costs and benefits } \\
\text { should be considered }\end{array}$ \\
\hline
\end{tabular}

1 Table 1. Recommendations for PA screening in different categories of patients. * It must be

2 acknowledged that the prevalence is calculated including also patients not affected by arterial

3 hypertension and it is expected to double if considering only patients affected by arterial hypertension. 
4

5

\begin{tabular}{|l|c|c|}
\hline & PRA (ng/ml/h) & DRC (mU/L) \\
\hline PAC (ng/dL) & 20 & 1.3 \\
\hline PAC (pmol/L) & 30 & 2 \\
\hline & 550 & 2.7 \\
\hline & 830 & 36 \\
\hline & 1100 & 55 \\
\hline
\end{tabular}

6 Table 2. ARR cut-off values, depending on assay. Adopted conversion factor is: aldosterone 1

$7 \quad \mathrm{ng} / \mathrm{dL}=27.7 \mathrm{pmol} / \mathrm{L}$.

8

9

10

11 


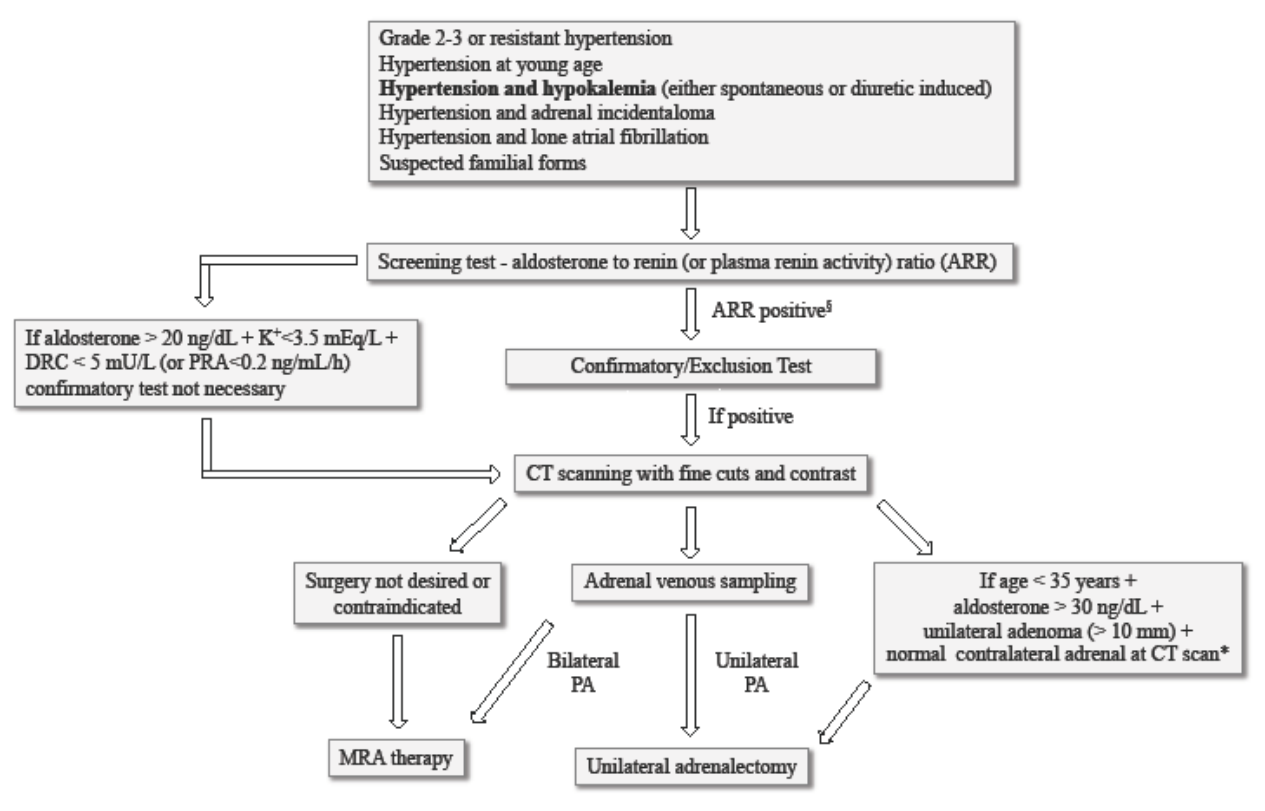

